\title{
Malnutrition Evidence and Solutions for Pakistan
}

\author{
Muhammad Sarwat Mirza* \\ Chief Health and Research Health and Nutrition Development Society (HANDS) Pakistan
}

*Corresponding author: Muhammad Sarwat Mirza, Chief Health and Research Health and Nutrition Development Society (HANDS) Pakistan

\section{Malnutrition Evidence in Pakistan}

Nearly one in three persons globally suffers from at least one form of malnutrition: wasting, stunting, vitamin and mineral deficiency, overweight or obesity and diet-related NonCommunicable Diseases [1]. Malnutrition is widely known as under-nutrition until and unless it is not specified. It accounts for at least half of all childhood deaths worldwide. Malnutrition is considered as fundamental cause of morbidity and mortality among the children [2,3]. It also poses a risk to children's physical and mental development, which results in poor academic achievement. Malnutrition affects the future health and socioeconomic development of children and the dynamic prospective of the society $[4,5]$. In the last two decades, there has been a little reduction in the prevalence of child malnutrition in Pakistan compared to other developing countries. The prevalence of all types of malnutrition in Pakistan was found to be higher than the global threshold value. It was found that malnutrition starts at an early age and remains persistent at later stages [6].

According to the National Nutrition Survey 2011, it has been reported that 13.4 million (43\%) of children under the age of five in Pakistan are moderately or severely stunted, 9.9 million (32\%) are moderately or severely underweight, and 4.8 million (15.1\%) children under five years of age are wasted. 50 percent of the children were anemic, and 33\% were anemic from iron deficiency [7]. The contributing factors in childhood malnutrition are low birth weight, inadequate breast feeding and exclusive breastfeeding, inappropriate complementary feeding, maternal education, lack of proper knowledge of nutrition, micronutrient intake, parity, birth spacing, household socioeconomic status, food insecurity, poor sanitation, vaccination, and infectious diseases [8]. Anemia among pregnant women has increased to 52 percent. Maternal anemia is associated with reduced birth weight and increased risk of maternal mortality. Anemia rates have been worsening over the past two decades. Children who are born with intrauterine growth restriction and low birth weight have a greater risk of morbidity and mortality. These children usually continued with slow growth rate resulted in stunting, slow mental growth and remained underweight [9]. Comparison of National Nutrition Survey 2001,
2011 and PDHS 2017-18 showed that over the last 18 years there is slight improvement in few aspects of malnutrition but generally the malnutrition status among children and women is stalling or further deteriorated (Table 1).

Table 1.

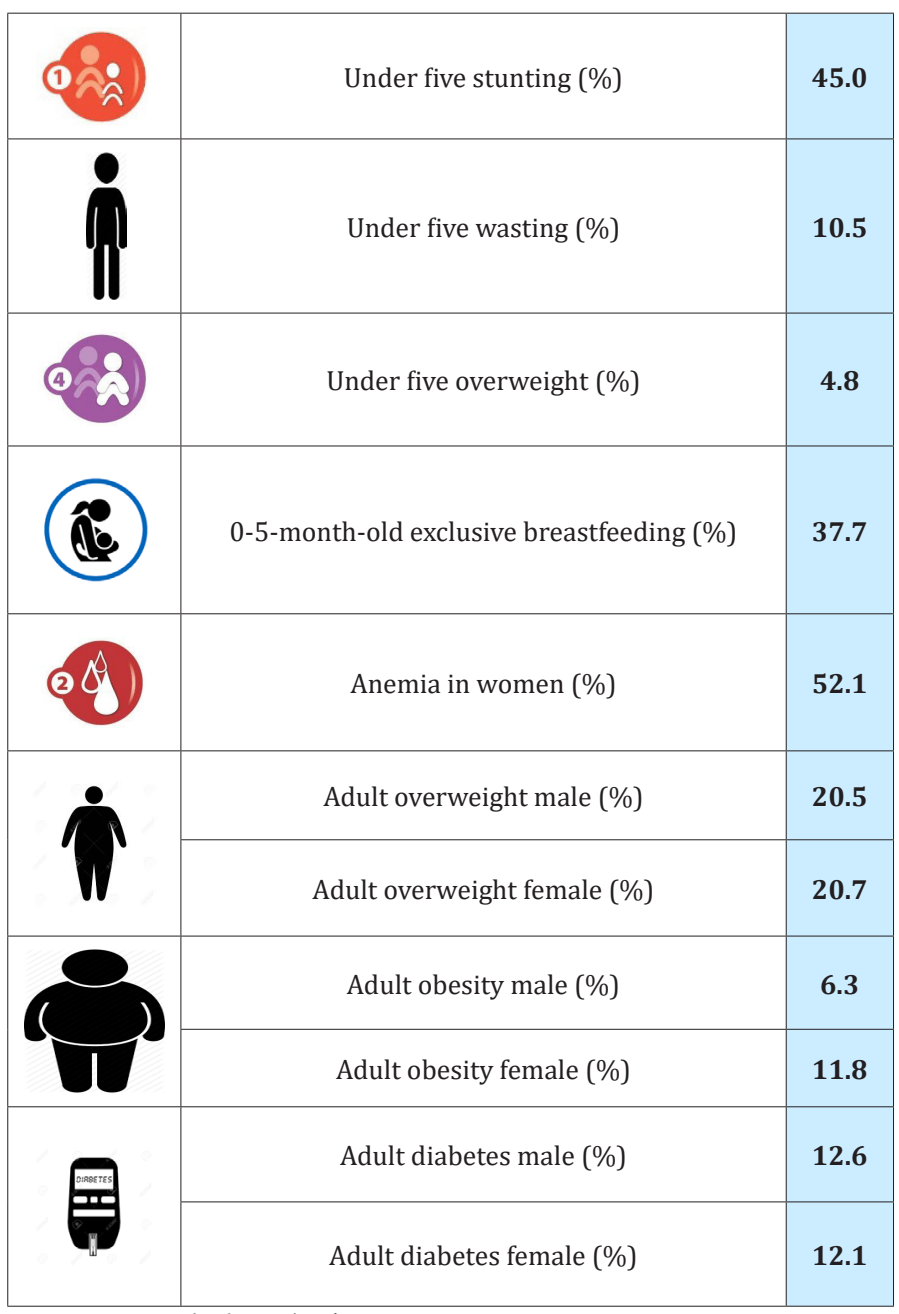

Current Statistics: (Pakistan SUN Secretariat Report 2017-18, P\&D Department) 
Iodine deficiency among women and children has decreased (improved).

a) Anemia among children and Iron deficiency anemia among women have worsened.

b) The chronic malnutrition indicators such as Wasting and stunting among children has worsened.

c) Both women and children have showed many folds increase in the prevalence of Vitamin A deficiency. d) Still micro-nutrient deficiencies are highly prevalent among children and women

Malnutrition has a negative impact on cognitive development, school performance and productivity. Stunting and iodine and iron deficiencies, combined with inadequate cognitive stimulation, are leading risk factors contributing to the failure of children to attain their full development potential (Figure 1). Each 1\% increase in adult height is associated with a $4 \%$ increase in agricultural wages and eliminating anemia would lead to an increase of $5 \%$ to $17 \%$ in adult productivity [10].

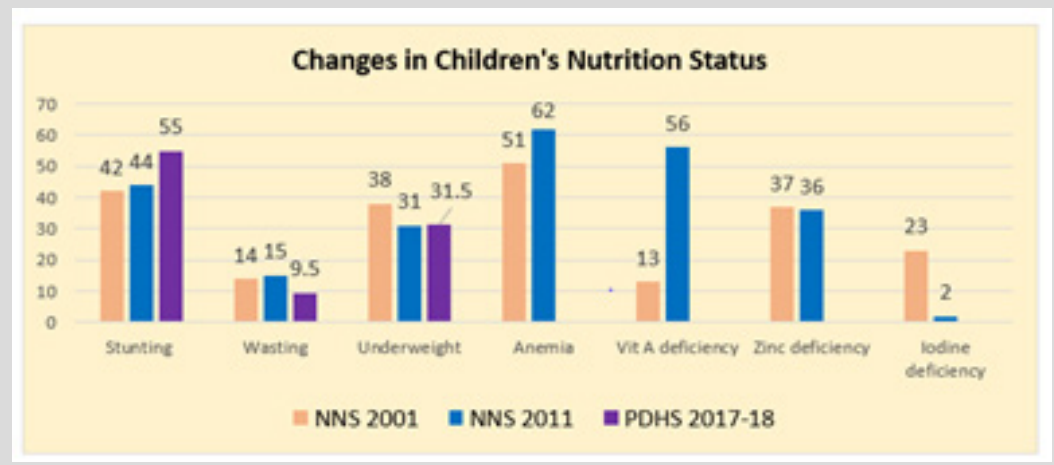

Figure 1.

\section{Food Security}

Food security [is] a situation that exists when all people, at all times, have physical, social and economic access to sufficient, safe and nutritious food that meets their dietary needs and food preferences for an active and healthy life (defined by The Food and Agriculture Organization (FAO). Despite Pakistan's strong agricultural base, food insecurity is widespread (Figure 2). According to The State of Food Security in Pakistan, 44 percent of households consume less than 2,350 Kcal per adult equivalent per day [11], the accepted normative standard set by Ministry of Planning Development \& Reform. The food security situation showed no signs of improvement since the last food insecurity assessment conducted by the United Nations in Pakistan (WFP Report 2009), which revealed that $51 \%$ of the population was food insecure. The situation has, in fact, deteriorated further. This will have serious implications on the nutrition, growth and health of the Pakistani population [12]. Despite growing levels of food production, economic access to food remains a major challenge in Pakistan. If available food is not accessible to the population, food security cannot be achieved. A household's access to food is a measure of its income, food distribution and the market prices of food items. Official estimates consider 29.5 percent of Pakistan's population 'poor' with reference to the revised national poverty line of PKR $3,030.32$ [13]. However, multidimensional poverty is estimated to affect 38.8 percent of the population when severe deprivations in education, health and living standards are considered. Poverty is most prevalent in eastern Sindh, western Balochistan and pockets of KP and Punjab [14]. The Food Consumption Score (FCS1) a proxy indicator of food security is a composite score based on dietary frequency, food frequency and relative nutrition importance of different food groups consumed at the household's level. The recent drought assessment in Sindh revealed that overall, around 18 percent of households have 'acceptable food consumption', 41 percent have 'poor consumption' and another 41 percent have 'borderline consumption' [15].

\section{Changes in Women Nutritional Status}

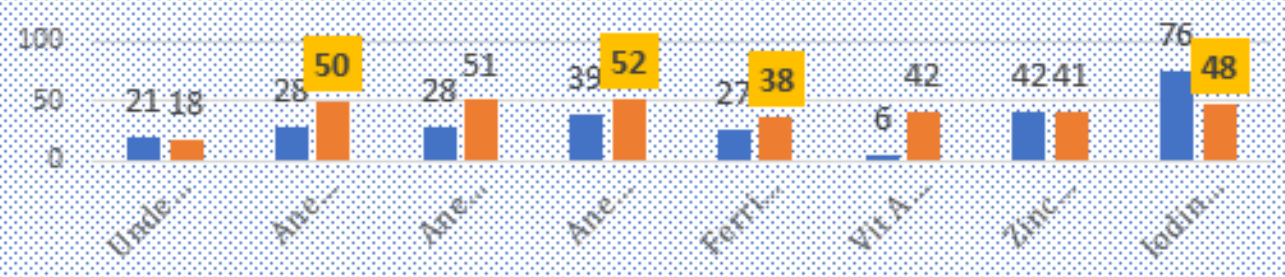

$\mathrm{NAN} 2001 \mathrm{NNS} 2011$

Figure 2. 


\section{Key Issues Related to Food Insecurity in Pakistan}

I. Access to food is a major challenge. Poverty is one of the biggest barriers to access to food. Additionally, high food cost and access to market of rural communities are major contributors.

II. Most of the households spend half (49 percent) of their monthly expenditure on food, on average, a proportion which increases among the poor.

III. Roughly half of Pakistan's population is energy deficient, consuming fewer calories than those required for a healthy life.

IV. Dietary diversity is limited in Pakistan, especially among poor and marginalized groups who follow a fixed pattern of food intake and consume a narrow variety of nutrients. One of the resulted outcomes is micro-nutrient deficiencies.

V. Whether an individual consumes-or not-nutritious food is contingent upon a myriad of factors, ranging from the availability of certain foods, how convenient they can be turned into meals, or simply, if they meet consumers' tastes. But above all, the high cost of food remains the most critical barrier to proper nutrition and affects the poor more than the rich. And in Pakistan, where malnutrition persists in multiple forms, the cost of nutritious food is prohibitive.

VI. The ready to use supplementary food are not available in the market and only available from limited sources on high cost.

\section{Burden of Non-Communicable Diseases}

Pakistan is facing double burden of Malnutrition as reported by National Nutrition Survey and latest data shared by Pakistan SUN Secretariat Report 2017-18, Ministry of Planning and Development. According to these reports adult overweight and obese person are $30 \%$, mostly residing in urban locations. Among male adults obese and overweight are 27 percent and slightly more female adults $32 \%$ are obese and overweight. The major contributing factors are the dietary pattern and habits leading to inappropriate consumption of food including consumption of more energy dense foods rather than the nutrient-dense foods, and consumption of artificial foods. These malnutrition states lead to two major non-communicable diseases including Hypertension, cardiovascular diseases and Diabetes.

\section{Solutions}

\section{Strategy for Prevention and Management of Malnutrition}

It is established fact that a malnourished child will face poorer outcomes as an adult. In Pakistan, where malnutrition persists in multiple forms, improving nutrition in the early stages of life is critical to a child's future development and health. The path toward better nutrition includes adequate maternal and childcare, access to better sanitation facilities, health services, and naturally, nutritious foods.

\section{Community based Primary Health Care interventions with special focus on Nutrition specific interventions for Children and Women such as}

The preventive measures must focus the children under five years of age, adolescent girls and women including pregnant and lactating mothers. The first 1,000 days from the start of a woman's pregnancy to a child's second birthday offer a window of opportunity for preventing under nutrition and its consequences. We should target this period with support for breastfeeding, nutrition-rich foods for infants and micronutrient supplements for mother and children. These nutrition specific interventions may be effectively implemented through primary health care services by community based Marvi workers and supervisor LHVs for quality technical services. The effective strategic plan should be devised including

a) Primary Health Care interventions (community-based education of mothers, health and nutrition services for prevention of malnutrition by promoting preparation of diversified appropriate meal (age appropriate) at home).

b) Manufacturing and Provision of Ready to Use Supplementary and Therapeutic Food --- for acutely malnutrition children, pregnant and lactating women.

c) Manufacturing and Provision of Multiple Micro-nutrient supplement (including iron and folate) tablets for pregnant and lactating women and Multiple Micro-nutrient sachet for children (6 - 24 months).

Provision of antenatal care, counseling about balance diet and provision of iron-folate supplements to all pregnant women through services within villages Referral strategy for safe institutional deliveries through linkages with Public sector health facilities Promotion of breast feeding ensuring three Es including Early initiation inclusive of colostrum, Exclusive breast feeding and Extensive breast feeding for 2 years. Engage the communities in vigorous campaigns to promote breastfeeding at the local level. Prevention of stunting and wasting through promotion of Infant and young child feeding as education of mother on appropriate diet preparation and feeding based on dietary diversity. Promote local dietary recipes through cooking demonstration. Use of Positive Deviation approaches for effective behavior change and correct practices by the mothers Growth monitoring of all children under five years of age quarterly and marked on growth cards for learning of mothers for linear growth follow up of each child Provision of multiple micro-nutrient (MNN) sachet for each child of 6-24 months of age Identification of children with Severely Acute Malnutrition and Moderately Acute Malnutrition and their community based management by provision of Ready to Use Supplementary Food (RUSF --- produced locally as Acha Mum packets by Ismail industries) and Ready to Use Therapeutic Food (RUTF --- provided by Unicef) for period of at least 2 months. Additionally, encouraging mothers to feed home-made meals to the children. 


\section{Strategy for Improving Food security at Community and household level}

The most energy-dense foods (cereals, oils and fats, sugars) generally had the most stable prices, showing the least inflation. These foods generally have a longer shelf life for storage and transportation. Food security and agriculture policies have emphasized energy-dense foods for the last several decades. The nutrient-dense foods such as legumes, lentils, animal source food, vegetables and fruits tend to be highly perishable, usually available on high cost, mostly not available in poor settings or unaffordable by the poor communities.

\section{Strengthening of Regulation of Legislation on milk substitutes}

There is a need to develop or where necessary strengthen legislative, regulatory and/or other effective measures to control the marketing of breast milk substitutes in order to ensure implementation of the International Code of Marketing of Breastmilk Substitutes and relevant resolutions adopted by the Health Assembly.

\section{Food security assurance thru Food Points in rural areas}

For food security, increased access to foods of good nutritional quality should be ensured in all local markets at an affordable price all year round, particularly through support to smallholder agriculture and women's involvement. Food points /enterprises may be developed at villages levels, to ensure the availability of recommended food items at affordable cost. For establishing these food points or enterprises, a grant of $20000 /$ - to community-based health worker may be provided. These workers may be connected to UC level wholesale shop keeper or suppliers. The system should ensure the promotion and availability of micro-nutrient fortified food such as iodized salt, wheat flour with iron, and edible oil with vitamin A \&D at affordable prices within communities.In addition, to food enterprises, community cooking sites / spot may be established to prepare the nutrient-dense meals which would be available for malnourished children (at least one meal for a day) at an affordable cost. The recipes are already devised and suggested by the Unicef, Nutrition support program and HANDS PHC program. The major food items for these meals would be based on chickpeas, lentils/ legumes, rice, porridge, dairy products, eggs, edible oil (enriched with Vit A \& D), and iodized salt.

\section{Food packaging and Supply system}

The food packaging and supplier agency may be formed to establish and ensure the functional food supply chain system. This agency may also play a vital role in managing and controlling the market price of the nutrient-dense and energy-dense foods. The government or concern organizations may play vital role in developing food supply chain system to ensure the availability on affordable cost of nutrient-dense foods in addition to energy-dense foods in the poor settings.

\section{Partnership with Food industry for Ready to Use food}

Additionally, strategic partnership may be developed with the food products manufacturing industries. The high energy and nutrient-dense ready to use food items may be produced by these industries on affordable cost for the treatment of acute malnourished children, pregnant and lactating women. Currently cost of treating one malnourished child by giving these ready to use food is ranged from Rs. 5500 to Rs. 10000/=.

Following food products may be produced as per demand:

i. Ready to Use Supplementary Food (RUSF) for Moderately Acute Malnutrition (MAM) Children

ii. Ready to Use Therapeutic Food (RUTF) for Severely Acute Malnutrition (SAM) Children

iii. Ready to Use Supplementary Food for pregnant and lactating women --- Mamtaa

iv. Multiple Micro-nutrient supplement sachet for children

v. Multiple Micro-nutrient supplement tablets for women

\section{District Level Resource Centers}

These resource centers may be established to serve the purpose of addressing and improving the food security issues at large scale or district level. These centers should develop strategic partnerships with agriculture institutes for technical support and oversight. These centers may perform the following tasks:

a) Support farmers by providing drought resistant and drought tolerant crops, inputs, and promotion of climate smart agriculture. Specifically, provide drought resistant seed of cereals, fodder, pulses, legumes, vegetables and shrubs plantation.

b) Introduction and up scaling of bio-saline agriculture

c) Capacity building of farmers through Farmers Field Schools (FFS), Junior Farmer Field Schools (JFFS), Farmers Business School (FBS) and Women Open Schools (WoS)

d) Introduction of drought tolerant fruit, fodder and shrubs plantations

e) Soil management through proper fertilization

f) Helping communities in applying No-till/reduced tillage systems

g) Facilitating farmers Usage of crop rotation/cropping systems

h) Strip farming as required centers

i) Establishment of community seed banks

\section{Strategy for Reducing the Burden of Obesity and Non-Communicable Diseases}

Information, Education and Communication material development: The information and education material may be used in large scale in printing form and by developing short video sessions based on healthy dietary habits and balance diet.

Halfway Healthy Spaces: The hospitals spaces such as waiting areas and OPD areas may be utilized for conducting these sessions. These may be promoted as halfway health spaces. 


\section{References}

1. Black RE, Victora CG, Walker SP, Bhutta ZA, Christian P, de Onis, et al. (2013) Maternal and child undernutrition and overweight in lowincome and middle-income countries. Lancet 382: 427-451.

2. Meshram II, Arlappa N, Balakrishna N, Rao KM, Laxmaiah A, et al. (2012) Trends in the prevalence of undernutrition, nutrient and food intake and predictors of undernutrition among under five-year tribal children in India. Asia Pac. J Clin Nutr 21: 568-576.

3. (2018) Children: Reducing Mortality. Available online. World Health Organizatio.

4. Asad N, Mushtaq A (2012) Malnutrition in Pakistani children, its causes, consequences and recommendations. J Pak Med Assoc 62: 311.

5. Ali, SS Karim, N Billoo, AG Haider (2005) Association of literacy of mothers with malnutrition among children under three years of age in rural area of district Malir, Karachi. J Pak Med Assoc 55 :550-553.

6. Stevens, GA Finucane, MM Paciorek, CJ Flaxman, SR White, et al. (2012) Trends in mild, moderate, and severe stunting and underweight, and progress towards MDG 1 in 141 developing countries: A systematic analysis of population representative data. Lancet 380: 824-834.

7. (2011) Planning Commission, Government of Pakistan, Pakistan Institute of Development Economics. National Nutrition Survey; Pakistan.

8. Di Cesare, M Bhatti, Z Soofi, SB Fortunato L Ezzati, et al. (2015) Geographical and socioeconomic inequalities in women and children's nutritional status in Pakistan in 2011: An analysis of data from a nationally representative survey. Lancet Glob. Health 3: e229-e239.

9. (2010) United Nations System Standing Committee on Nutrition, Progress in nutrition: Sixth report on the world nutrition situation. Geneva, United Nations System Standing Committee on Nutrition Secretariat.

10. (2014) Comprehensive Implementation plan on Maternal, Infant and Young Child Nutrition", WHO.

11. FAO, IFAD, UNICEF, WFP, WHO (2017) The State of Food Security and Nutrition in the World 2017: Building resilience for peace and food security. Rome, Food and Agriculture Organization.

12. Planning Commission (2016) Ministry of Planning, Development \& Reform. Pakistan's Revised Poverty Line. Islamabad, Government of Pakistan.

13. WFP, FAO, UNICEF (2016) Ministry of National Food Security and Research.

14. UNDP, OPHI, Planning Commission (2016) Multidimensional Poverty in Pakistan. Islamabad, UNDP/Ministry of Planning Development \& Reform.

15. Unicef FAO, Acted, HANDS, IOM, WFP, WHO, et al. (2019) "Sindh Drought Needs Assessment (SDNA) Report Jan 2019".
This work is licensed under Creative Commons Attribution 4.0 License

To Submit Your Article Click Here: Submit Article

DOI: 10.32474/RRHOAJ.2019.03.000175

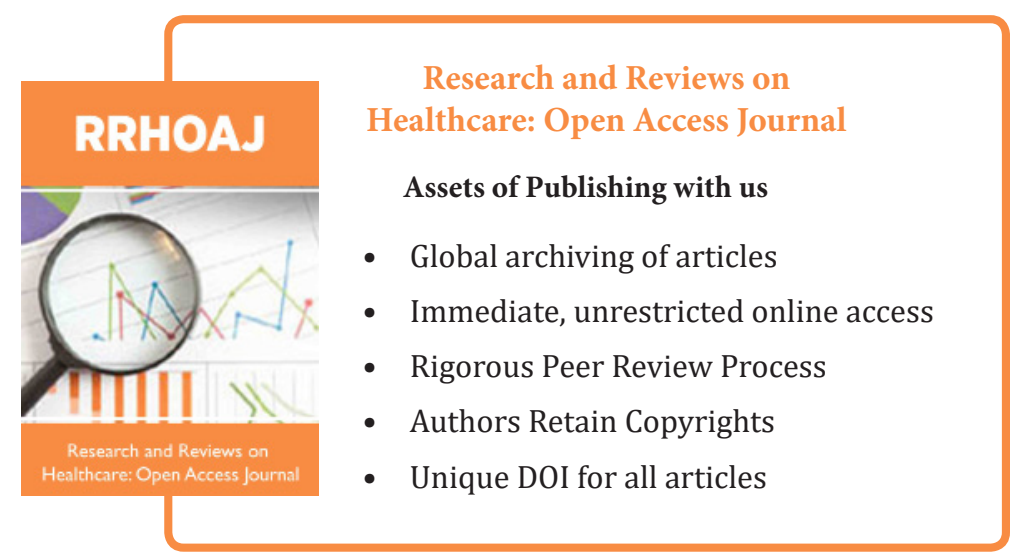

